\title{
The Experience of Improvising in Organizations: A Creative Process Perspective
}

\author{
Colin M. Fisher \\ University College London \\ colin.fisher@ucl.ac.uk \\ Frank J. Barrett \\ Naval Postgraduate School \\ fbarrett@nps.edu
}

\section{Acknowledgements}

We would like to thank Matt Cronin, Sarah Harvey, and the UCL School of Management Reading Group for their feedback and advice on earlier versions of this manuscript. We would also like to thank Sharon Kim and Erik Helzer for their invitation and encouragement to develop this manuscript, as well as Phillip Phan and two anonymous reviewers for their feedback throughout the process. We would also like to thank Teresa Amabile and J. Richard Hackman for their encouragement and support for studying improvisation and creativity. 


\title{
The Experience of Improvising in Organizations: A Creative Process Perspective
}

\begin{abstract}
In this paper, we explore how improvisation is experienced by people in organizations, conceptualizing improvisation as a creative process. We draw on a small number of scholarly accounts of the experience of improvising in organizations, and compare and contrast them with accounts from the performing arts. In both cases, improvising evokes simultaneous exhilaration and fear, as well as experiences of non-goal-directed action. In many organizational contexts, however, improvisation is normatively discouraged, which heightens the fearful aspect of the experience. This leads many workers to avoid improvising, using it as a method of last resort and even hiding its use. Thus, improvisation is seldom used in favorable circumstances nor practiced to the point of familiarity or expertise. We discuss the implications of these insights for research and practice of improvisation and creativity in organizations, and propose a research agenda for the experience of improvising in organizations.
\end{abstract}

Keywords: Improvisation, subjective experience, creative process, creativity 
People in organizations often encounter unforeseen obstacles at work, fumble through potential solutions extemporaneously, work with the materials at hand, and come upon new insights, alternative courses of action, or product innovations. Organizational scholars have described such activities as improvisation. For instance, Barrett (2012) described a Xerox repair technician who had to deviate from their repair manual and draw on prior experience in real-time to fix a recalcitrant machine in a novel way and save face with the customer. In another example, Fisher and Amabile (2009) recounted how, at an informal lunch, engineer George Hatsopoulos responded to a Ford Motor Company executive's complaint about a new federal regulation. Hatsopoulous spontaneously promised to deliver an instrument to meet the regulation, even though he had no product or prototype; his promise led to orders from several major auto manufactures and the founding of the Thermo-Electron corporation.

Improvisation entered the discourse on organizational studies as a suggestive metaphor borrowed from jazz and theatre improvisation, but has moved beyond that metaphor as a way to construe real-time action and unplanned unfolding events, focused on their novel and spontaneous nature (Cunha, Miner, \& Antonacopoulou, 2017; see Hadida, Tarvainen, \& Rose, 2015 for a comprehensive review of definitions). For instance, Barrett (1998) proposes improvisation is "fabricating and inventing novel responses without a prescriptive plan and without certainty of outcomes; discovering the future that action creates as it unfolds" (p. 605). Bastien and Hostager (1988) define improvisation as "the invention, adoption and implementation of new ... ideas by individuals within the context of a shared awareness of the group performance as it unfolds over time" (p. 583). Cunha, Cunha, and Kamoche (1999) review several definitions and compile them as: "Conception of action as it unfolds, by an 
organization and/or its members, drawing on available material, cognitive, affective, and social resources"(p. 302).

Interest in organizational improvisation has grown over the past two decades (Hadida et al., 2015), in part because organizational life is changing fast: technological and social innovations are emerging at an unprecedented rate. In such circumstances, detailed plans and existing routines may be inadequate or impossible, leading people to improvise. Research suggests that improvisation can generate novel and useful solutions in organizations (Fisher \& Amabile, 2009), such as real-time problem solving by managers in fast-paced industries (e.g., Brown \& Eisenhardt, 1997; Crossan \& Sorrenti, 1997), entrepreneurs dealing with unexpected problems and opportunities (e.g., Baker \& Nelson, 2005; Hmielski \& Corbett, 2008), or responses to life-threatening crises that go beyond the scope of people's training (e.g., Hutchins, 1991; Weick, 1993). In short, improvisation can be an important source of creativity ${ }^{1}$ at work and can have lasting consequences for organizations (e.g., Barrett, 1998; 2012; Smets, Morris, \& Greenwood, 2012).

\footnotetext{
${ }^{1}$ Following prior research, we regard creativity as focused on the generation of new ideas, while innovation as focused on implementing new or improved ideas. We agree with prior research that explicates the relationship between creativity and innovation (i.e., Anderson, Potočnik, \& Zhou, 2014; Amabile \& Pratt, 2016; Perry-Smith \& Mannucci, 2017), regarding creativity as a necessary (but not sufficient) input into the innovation process. However, creativity is often also involved in every day problem solving that is unrelated to innovation (Amabile \& Pratt, 2016). Because we are focused on the experience of improvising, which is the experience of generating new ideas in real time, we use the term creativity, rather than innovation, here.
} 
Many organizational scholars have focused on the outcomes of improvisation for organizations - the extent to which it leads to learning (Miner, Basshoff \& Moorman, 2001), faster innovation (Eisenhardt \& Tabrizi, 1995) or entrepreneurial performance (Hmielski \& Corbett, 2008). However, we focus on the experience of improvising in organizations - what people think and feel during the process of improvising. Indeed, two recent reviews of organizational improvisation pointed out that understanding the experience of improvising (i.e., emotions, interpretations) is one of the most important gaps in the literature (Cunha et al., 2017; Hadida et al., 2015). To understand the experience of improvising, we take a process perspective on creative action (Cronin \& Lowenstein, 2018; Harvey, 2014; Perry-Smith \& Mannucci, 2017). Process perspectives can reveal, "the meaning of processes for individuals - that is, the way they are experienced," (Langley, 1999, p. 707). Further, how a process is experienced may help explain when and why people engage in it, making it both an input to and a part of long-term well-being (Amabile \& Kramer, 2011).

In this paper, we explore two questions: (1) How is improvisation experienced by people in organizations? and (2) What implications does this experience have for research on improvisation and creativity in organizations? To address these questions, we draw on a small number of scholarly accounts of the experience of improvising in organizations, and compare and contrast them with accounts of improvising in the performing arts. We argue that experience of improvising is characterized by simultaneous exhilaration and fear, as well as experiences of non-goal-directed action. In many organizational contexts, however, improvisation is normatively discouraged, which heightens the fearful aspect of the experience. This leads many workers to avoid improvising, using it as a method of last resort and even hiding its use. Thus, improvisation is seldom used in favorable circumstances nor practiced to the point of familiarity 
or expertise. We discuss the implications of these insights for research and practice of improvisation and creativity in organizations, and propose a research agenda for the experience of improvising in organizations.

We should note that this paper is not intended to be a comprehensive review of antecedents or outcomes of improvisation or creativity in organizations. Excellent recent reviews already exist on both organizational creativity (Amabile \& Pratt, 2016; Anderson et al., 2014) and improvisation (Cunha et al., 2017; Hadida et al., 2015). However, this paper is distinct from these reviews in that we focus on the subjective experience of improvising, rather than on the inputs or outcomes, and explicitly link improvisation and creativity via a process perspective.

\section{IMPROVISATION AS A SPONTANEOUS CREATIVE PROCESS}

\section{Prior Research on Improvisation in Organizations}

Although we focus on the experience of improvising, we briefly review important antecedents and consequences of improvising in organizations that illuminate this experience. Improvisation in organizations emerges when people encounter novel, complex, urgent, and consequential situations (e.g., Smets et al., 2012). In such situations, improvisers engage in bricolage, making do with whatever resources are at hand (Baker \& Nelson, 2005). For instance, in his seminal article, Weick (1993) analyzed how the team leader in the unexpectedly out-ofcontrol Mann Gulch fire spontaneously employed an "escape fire," in which he burned a small area and laid down in the ashes. This technique deprived the fast-approaching blaze of fuel, such that it passed around the spot where he laid, and allowed him to survive the oncoming flames. Weick noted that such novel behaviors are surprising because, "what we do not expect under life-threatening pressure is creativity," (639). Indeed, in such immediate and essential moments, 
people can spontaneously bring their experience and expertise to bear in unexpected ways (Barrett, 2012). Improvisation has been shown to help managers navigate dynamic and uncertain environments, such as the fast-paced changes in high tech industries in the mid-1990's (Brown \& Eisenhardt, 1997; Crossan \& Sorrenti, 1997) or leaders of fledgling entrepreneurial enterprises dealing with unforeseen problems and opportunities (Baker \& Nelson, 2005).

Such novel and urgent situations do not occur only in major crises or highly dynamic environments; they are also embedded in everyday work practices (Orlikowski, 1996; Tsoukas \& Chia, 2002). For instance, Smets and colleagues (2012) found that lawyers drafting legal documents for a merger across English and German jurisdictions engaged in "situated improvising" when institutional logics conflicted or no precedent was available. The results of these small improvisations then began to radiate throughout the field, leading to larger scale change in the industry, in which the originally improvised solutions were refined and reproduced. Similar situations in which novel actions emerge in response to novel and urgent situational demands that are not full blown crises have also been documented in new product development (Miner et al., 2001) and negotiations (Balachandra et al., 2007; Long Lingo, Fisher, \& McGinn, 2014). The results of these improvisations may or may not be retained by the organization or the field, but, in the moment, they can generate solutions to present-focused problems.

Like any process, improvisation is not inherently good or bad for people or organizations. Although research on improvisation in organizations initially focused on its potential benefits for organizations, improvisation can also have undesirable consequences, such as undermining coordination (Leybourne and Sadler-Smith 2006) or inhibiting long-term learning (Miner et al., 2001). Although in its early stages, research suggests several factors that facilitate effective 
improvisation. First, improvisation is most effective when it is guided by "minimal structures" simple rules that permit actors to coordinate without strictly constraining their actions - that partially define goals and interaction patterns (e.g., Barrett, 1998; Vera et al., 2016). Further, improvisation is likely to succeed when actors are attentive to each other and the situation (Bigley \& Roberts, 1999; Fisher \& Amabile, 2009). Other important factors theorized to facilitate improvisation include an experimental organizational culture and expertise in taskwork and teamwork (Crossan, Cunha, Vera, \& Cunha, 2005; Vera \& Crossan, 2005).

\section{Contrasting Improvisation and Composition}

At its core, improvisation is a creative process - a means by which people can generate responses that are both novel and useful (Fisher \& Amabile, 2009). Most organizational scholars conceptualize creativity as a property of products or people: the extent to which an outcome is judged to be novel and useful (e.g., Amabile, 1996) or individuals' propensity to produce such outcomes (e.g., Gough, 1979; Zhou, 2003). This is distinct from research on creative processes, which comprise, "the steps involved in the creation of a novel work, whereas creative product refers to a final work that the social context accepts as novel and useful," (Mainemelis, 2010, p. 560). In other words, creative processes are intended to generate creativity, but can vary in the degree to which they succeed at doing so (Cronin \& Lowenstein, 2018; Drazin, Glynn, \& Kazanjian, 1999). Because improvisation is a process for generating novelty that is also intended to be useful, it is, by definition, a creative process. Like any creative process, engaging in improvisation does not mean that improvisers always generate creative outcomes-the results of improvised actions can vary in the extent to which they are regarded as novel or useful (Crossan et al., 2005). 
In a creative process perspective, improvisation is best contrasted with the conventional view of the creative process in organizations - composition (Fisher \& Amabile, 2009). In the compositional process, new ideas develop over long time horizons, such as Hollywood studios writing and producing a film (Perry-Smith \& Mannucci, 2017), design firms coming up with new products and services (e.g., Fisher, Amabile, \& Pillemer, 2018; Sutton \& Hargadon, 1996), or pharmaceutical companies developing new drugs (Amabile \& Kramer, 2011). Organizational scholars have viewed the compositional process as a linear progression of phases, extending Wallas's (1926) model (Harvey, 2014). In a representative example, Amabile and Pratt (2016) summarized five main phases of the creative process: (1) task presentation, in which a goal or problem is identified; (2) preparation, during which resources needed for performing the creative task are acquired; (3) idea generation, during which people produce possible solutions to pursue; (4) idea validation, when creators check possibilities against their criteria for success; and (5) outcome assessment, in which creators decide whether or not further iteration to an earlier phase is necessary, based on the results of the idea validation phase.

Improvisation, however, is at odds with phase models of the compositional process in several ways (Fisher \& Amabile, 2009; Sawyer, 2000). These models presume that the purposes of action are well-defined in advance. Beginning with "task presentation" assumes a motivated and intentional endeavor, in that the task or problem to be solved is clear from the outset. In improvisation, on the other hand, what is to be done emerges as action unfolds, and goals are clear only in retrospect (e.g., Weick, 1998). Further, posing a step of "outcome assessment" and separating idea generation and validation assumes that the creative process results in products that are separate from their enactment, whereas, in improvisation, these must occur simultaneously. Last, these models assume that it is possible to prepare after a task is presented; 
however, creativity emerging spontaneously in real-time would involve preparation only before a particular task is presented.

These differences in activity sequences lead to other important differences between composition and improvisation. In composition, one can step out of the process without ending it - switching attention to other matters (Elsbach \& Hargadon, 2006; Lu, Akinola, \& Mason, 2017; Madjar \& Shalley, 2008), or allowing ideas to "incubate" (e.g., Hélie \& Sun, 2010). In improvised action, stepping out of the time and flow of the process would end it entirely. Further, it is possible to revise in composition, but not in improvisation: when composing, one can amend or discard ideas, but, when improvising, actors must work with the consequences of their prior actions. As we discuss below, these differences in process create important distinctions in the experience of improvising from composing.

\section{THE EXPERIENCE OF IMPROVISING}

Accounts of improvising in the performing arts and bureaucratic organizations note that improvisation is simultaneously "exhilarating and perilous" (Barrett; 1998, p. 606). But, the balance of exhilaration and peril varies widely between these two settings. In the performing arts, the danger of improvisation is part of what engenders exhilaration, leading to experiences of transcendence. In other contexts, however, the perilous dimension of improvisation may dominate people's experiences, such that actors find it stressful and unpleasant.

\section{The Experience of Improvising in the Performing Arts}

Research on performing arts, such as jazz (Peplowski, 1998), theater (Spolin, 1983), and pick-up basketball games (Eisenberg, 1990), suggest that improvising is interpersonally risky 
because improvisers test the limits of their own capabilities and sometimes fail in embarrassing ways. In contrast to executing the products of compositional creativity, like an orchestral performance of classical symphony, or a figure skater executing a carefully choreographed routine, improvised performances are characterized, and even valued, because they put risk of failure on public display (Berliner, 1994; Nachmanovitch, 1990). In fact, the danger of failure may be part of what creates the experience of exhilaration. Courting the perilous edge of one's known capabilities focuses improvisers on the present moment, rather than on previously rehearsed routines. For example, Miles Davis, an eminent jazz trumpet player, explained why he deliberately made his bandmates uncomfortable in performances and recordings:

See, if you put a musician in a place where he has to do something different from what he does all the time, then he can do that—-but he's got to think differently in order to do it...He's got to take more risks....Because then anything can happen, and that's where great art and music happens (Davis \& Troupe, 1991, p. 220).

As with many artistic improvisers, Davis valued times when "anything can happen" as opportunity for extraordinary creativity. To access such moments, one must be immersed in the present moment, rather than relying on the past or worrying about the future. One merely acts and responds to the immediate; there is no time to consciously consider alternatives or their implications. Indeed, a radical focus on the present is one of the most important elements of improvisation, in which "past and future blend together in a deep experience of the present" (Crossan et al., 2005, p. 139). In focusing intently on the present and seeking out situations that call out for novel responses, the perilous nature of improvisation can lead to experiences that artistic improvisers often describe as "transcendent"-exhilarating and timelessness feelings in which actors do not experience conscious control of their actions (e.g., Eisenberg, 1990). In such 
experiences, self-consciousness and a sense of individuality are subsumed into a present-centered and collective experience. In her classic book on theatre improvisation, Viola Spolin described this experience:
All of us have known moments when the right answer 'just came' or we did 'exactly the right thing without thinking.' Sometimes at such moments ... the 'average' person has been known to transcend the limitation of the familiar, courageously enter the area of the unknown, and release momentary genius within.... The intuitive can only respond in immediacy_right now. It comes bearing its gifts in the moment of spontaneity, the moment when we are freed to relate and act, involving ourselves in the moving, changing world around us. (Spolin, 1983, p. 4).

This quote highlights several important aspects of the experience of improvising in the arts. First, people do not experience ideation as intentional or effortful - there is no deliberation or consideration of possible responses. When improvising, people must rely on intuitive, rather than deliberative thinking (e.g., Dane \& Pratt, 2007; Dörfler and Ackermann, 2012; Stierand, Dörfler, \& MacBryde, 2014). The response emerges from the improviser immediately and almost without effort. That response then reshapes the situation and informs the actions that follow.

This experience of a lack of intentional control and rational consideration can lead to an expanded or absent sense of self. As improvising musician Steven Nachmanovitch put it,

For art to appear, we have to disappear. This may sound strange, but in fact it is a common experience. ... Mind and sense are arrested for a moment, fully in the experience. Nothing else exists. When we 'disappear' in this way, everything around us becomes a surprise, new and fresh. Self and environment unite. Attention and intention fuse. (Nachmanovitch, 1990, p. 51) 
The experience that Nachmanovitch describes here is closely akin to other experiences of the creative process, such as mindful awareness (Good et al., 2015), flow (Csikszentmihalyi, 1990) and timelessness (Mainemelis, 2001; 2002). Although improvisation can evoke these states, it is not synonymous with them because such experiences can also occur during repetitive practice of skills (Csikszentmihalyi, 1990) or meditation (Good et al., 2015). Those states need not evoke novel performances that characterize improvisation. Further, the experiences descried above are likely successful ones - having these kinds of experiences is often one of the goals of participating in sports or artistic improvisation. For instance, in filming the movie Dead Poet's Society, director Peter Weir suggested that lead actor Robin Williams improvise a few scenes to make him more comfortable and less self-conscious (Lazendorfer, 2015). Although these experiences are likely familiar to performing artists and may promote effective improvisation, they are unlikely to be the norm; indeed, even expert performers may rarely experience them (Eisenberg, 1990).

Two factors distinguish these experiences from those of composition. First, because composers can disengage from the task of creating, they can cool down their emotions and reflect on their actions, taking breaks or switching attention to other tasks (e.g., Hélie \& Sun, 2010). Further, the ability to revise reduces the costs of making mistakes. These factors should allow composers to experience less peril - of always being at the edge of what they can do - but may also lessen the exhilaration and the potential for transcendent experiences. Further, when composers experience exhilaration and transcendence, it may be examples of improvisation occurring within a larger compositional process.

\section{The Experience of Improvising in the Organizations}


Although the risks of improvisation may help performing artists to focus on the present and engender transcendent experiences, the perilous nature of repeatedly improvising on the job can be extremely stressful. In life-threatening accounts of improvising firefighters (Weick, 1993) or nautical crews (Hutchins, 1991), the stressful aspects of improvisation likely outweigh the exhilarating ones because the stakes are so high. Supporting this notion, Hmielski and Corbett (1998) found that entrepreneurs who lacked confidence in their abilities tended to lead slowergrowing ventures, but were more satisfied with their work when they improvised more. In contrast, although confident entrepreneurs tended to perform better, they reported lower levels of work satisfaction when they improvised more. The authors speculated that, as ventures grow, the consequences of failure become perceived as more severe, such that improvising (and its attendant risks) caused more stress for the confident and high-performing entrepreneurs than for the less confident and lower performing ones.

Indeed, constantly having to improvise on the job can lead to burnout (Hatch, 1999). For instance, one of the workers in Baker and Nelson's (2005) study of bricolage in entrepreneurial firms improvised an effective IT solution, but eventually quit his job, because he was "tired of trying to make that half-assed system run and then trying to explain why it couldn't do everything the real systems can do" (p. 350). Although the initial experience of creating may be challenging and exciting, continuing to craft make-shift solutions can result in further demands to improvise around them, becoming more tiresome than exhilarating.

Moreover, improvisation is normatively discouraged in many highly-regulated environments, adding to the stress involved in its use - even when improvising is necessary. Batista and colleagues (2016) found that emergency room medical workers often needed to improvise solutions that contradicted accepted protocols to protect patients' health, but then felt 
obligated to hide their improvisations to avoid scrutiny. Improvisation was thus pushed into the "underlife" of the organization, and was not formally recognized or discussed publicly. In such situations, improvising may be a risky deviation for actors, increasing the fearful nature of the experience.

Another important difference between improvisation and composition is that composition is often sanctioned by the organization (e.g., R\&D, new product development). In contrast, improvisation is often unsanctioned and, by definition, departs from standard operating procedures. Further, many organizations put a normative value on planning and rationality; relying on unplanned, spontaneous behavior may be quite uncomfortable, even when it is effective. As a manager in Brown and Eisenhardt's (1997) study of improvisation in a nascent high-tech industry remarked:

We do things on the fly. ... I've done some things at IBM and other companies where there is a very structured environment — these companies are failing and we are leading the way. I'm not comfortable with the lack of structure, but I hesitate to mess with what is working. . We've gotten away with it so far. (Brown \& Eisenhardt, 1997, p. 28).

As in this example, many managers find improvising aversive, seeing it as something that they have "gotten away with," rather than as a necessary or valuable process - even when improvisation is leading to success. Improvisation may even seem antithetical to the very notion of management and organization (Weick, 1998). Managers might feel threatened by encouraging workers to improvise - if workers can make up plans as they go, what role is there for management? Thus, improvisation is likely experienced quite differently from formally sanctioned, planned-for composition - even in dynamic environments in which improvisation may be all but inevitable. 


\section{A RESEARCH AGENDA FOR THE EXPERIENCE OF IMPROVISING}

Why is improvisation in the performing arts experienced differently from other organizational contexts? Certainly, the consequences of failure are part of the reason - failing to escape a life-threatening fire (Weick, 1993) or losing thousands of dollars for one's employer (Smets et al., 2012) can feel costlier than playing a bad solo in a jazz performance. Further, improvisation at work can be demanding over time - constantly having to make do can wear people down, especially when they are improvising out of necessity, rather than choice. Also, because improvisation goes beyond official rules and procedures, workers often fear the effects of acting outside of what is formally sanctioned, especially in traditional bureaucratic organizations with cultures that prize planning and rationality. These factors can tilt people's experience of improvising so far toward fear and away from exhilaration so as to make them hesitant to improvise except in the most desperate circumstances.

As noted above, improvisation is undoubtedly a process, yet it is often studied like a static entity (Cunha et al., 2017). We therefore recommend that future research address both the subjective experience of improvising and the processural nature of the phenomenon. Examining processes in organizations is often not as simple as creating variables to measure the frequency or quality of those processes (e.g., Langley, Smallman, Tsoukas, \& Van de Ven, 2013). Dating back to ancient Greece, social theorists have argued about whether to view processes as how entities change, giving primacy to things in the analysis, or to view entities as temporary instantiations and reifications of processes, giving primacy to processes in the analysis (Rescher, 1996; Tsoukas \& Chia, 2002). Process is often understudied, in part, because most organizational scholars view reality as composed of static entities, rather than of dynamic processes (Cronin \& 
Lowenstein, 2018; Tsoukas \& Chia, 2002). In contrast, process research has the potential to flip this ontology, such that the social world is made up of many interlocking processes, which we can artificially freeze into "things" that we analyze. Building on a process perspective, we propose theoretical lenses, research questions, and methodological considerations to advance the study of the experience of improvising.

\section{Theoretical Lenses}

Relax dualistic assumptions of ideation and creation. Improvisation does not neatly conform to the ways in which organizational researchers categorize action and experience; it inherently challenges assumptions about the relationships between processes and outcomes (Cunha et al., 2017; Weick, 1998). In particular, scholars typically use a "dualistic" epistemology to understand the creative process, in which knowing and doing are separate activities linked by individuals' intentional actions (i.e., a purposive-rational view of action). Dualism is especially clear in two aspects of creativity research. First, as we mentioned earlier, the initial steps in conventional models of the creative process (i.e., task presentation, preparation) imply a motivated and intentional endeavor, in which the purposes of action are defined in advance. Second, scholars often conceptualize ideas as mental representations, which artificially separates generating ideas from acting on them (e.g., Nonaka, 1994; Tsoukas \& Chia, 2002). Although ideas are central to creativity research (e.g., Gilson \& Litchfield, 2017), they are viewed as generated and stored in people's minds (e.g., "having an idea"), awaiting enactment or implementation. This dualistic, purposive-rational view is difficult to reconcile with improvisation, in which ideas are constituted through action (Barrett, 2000; Yanow \& Tsoukas, 2009) and the purposes of action become clear only in retrospect (Weick, 1998). 
When studying the experience of improvising, scholars should therefore adopt pragmatic views of knowledge and action, which de-emphasize plans and intentions. Pragmatic views emphasize action as embedded in, constrained by, and shaped by social interactions (Tsoukas, 2009). Following many earlier social theorists (e.g., Heidegger, 1962; Mead, 1934), Gergen (1985) argued that "knowledge is not something people possess in their heads, but rather, something people 'do' together" (p. 270). While purposive-rational views emphasize the "push" of intentions and choices on actions, pragmatist views emphasize the "pull" of social dynamics in evoking creative action (Joas, 1996).

Purposive-rational views can "hide" improvisational creative action (Joas, 1996) because scholars and practitioners may try to interpret experiences in terms of logic and personal agency. This overstates the role of intentional, goal-directed action in creative processes and understates the extent to which we improvise our way through organizational life. Rather than consciously choosing to pursue a goal, actors test out and revise courses of actions in real time as they observe themselves acting in the social world and see others and the environment respond. Means and ends are not separable, but intermingled. For instance, theatre improvisers must react to whatever other actors do - accepting the actions of others and responding to them without conscious deliberation, responding with some variation of "yes and..." (Vera \& Crossan, 2004). They do not choose the specific action to which they respond, nor can they take to prepare or generate possible solutions to choose from among - they must simply respond before the moment passes. These views are more consonant with the emerging picture of the creative process as shaped by social interactions and situations - fleeting moments of collaboration are often the source of creative ideas, in which neither party has complete ideas stored in their heads prior to the interaction, nor are their ideas merely added together (e.g., Hargadon \& Bechky, 
2006; Harvey \& Kuo, 2013). Pragmatic views of action can highlight these emergent dynamics, which are inherent to improvisation.

Adopt paradoxical frames of affect and experience. The experience of improvising also requires researchers to adopt non-dualistic views of subjective experience. Acting in novel ways in the presence of others feels dangerous not only because evaluators often reject novelty (Mueller, Melwani, \& Goncalo, 2012), but also because the real-time creating involved in improvisation pushes creators to their limits. Improvising sits on the razors edge between fear and exhilaration. Indeed, improvisation may be an extreme case of all creative processes, which brings these dual dimensions of creative experience to the surface.

We argue that the experience of the creative process would be better explained through paradoxical models of experience (Miron-Specktor, Gino, \& Argote, 2011), rather than thinking of discrete emotions as antecedents of creativity. Creativity researchers have debated how affect serves as an antecedent to creative productions, with studies finding that positive (e.g., Amabile, Barsade, Mueller, \& Staw, 2004), negative (e.g., George \& Zhou, 2002), and ambivalent (Fong, 2006) emotions are associated with creative outcomes. As Fong (2006) notes, people in organizations may commonly experience simultaneous, yet conflicting emotions. These conflicting emotions may be both a cause and effect of engaging in the creative process. In a process perspective, these dual experiences would inform each other over time, rather than being seen as two ends of a continuum between positive and negative. The interplay between experience and action are not independent and mutually exclusive, but interdependent and mutually constitutive.

\section{New Research Questions}


Antecedents of the experience of improvising. Our focus on the experience of improvising suggests new questions about the antecedents and consequences of this experience. We build on the premise that, although improvisation is experienced quite differently in the performing arts and in bureaucratic organizations, the tension between exhilaration and peril is present in both settings. Thus, the goal of future research should be to identity how organizational and personal factors affect the balance between these simultaneous experiences.

We first ask: How do personal and situational factors affect the experience of improvising? Prior research on situations that evoke improvisation suggests that members of organizations improvise when confronted with novel, complex, urgent and consequential situations (Smets et al., 2012). However, research has focused primarily on circumstances when people have almost no choice but to improvise because of changes in their environment. In such circumstances, organizational cultures that encourage experimentation and tolerate failure can help reduce the social costs of failure while improvising, which should lessen the experience of peril. Research has already revealed that more experimental organizational cultures lead to more effective improvisation because people do not fear punishment for trying new things (Crossan et al., 2005; Vera \& Crossan, 2005).

Further, one of the primary findings on organizational improvisation has been that minimal structures and simple rules allow people to improvise flexibly by defining points of coordination and out-of-bounds activities (Barrett, 1998; Eisenhardt \& Sull, 2001; Vera et al., 2016). Such structures should reduce the chances of coordination failures, thus lessening people's sense of fear when improvising. Expertise should have similar effects on the extent to which improvisation feels perilous or exhilarating (e.g., Crossan et al., 2005). The more skill and expertise one has in a domain, the more comfortable improvising is likely to be. For instance, 
acting out an improvised comedy skit should feel less dangerous to an experienced and wellpracticed performer than to a novice. However, further research is still needed to test how expertise, culture, and minimal structures work in tandem to affect people's experience of improvising.

The experience of improvising over time. The antecedents above should not only affect one instance of improvisation, but should also affect the extent to which actors are willing to improvise in the future - for good or for ill. It is thus necessary for researchers to look beyond single episodes of improvisation and investigate how the experience shapes further actions_-as well as the people and situations themselves.

First, people's improvisational capabilities may be influenced by their prior experiences with improvising, altering their expertise and perceptions of risk. Practice and experience are critical ingredients for improvisation in the performing arts (e.g., Berliner, 1992; Peplowski, 1998) and likely contribute to positive experiences of it. Whether a situation is even viewed as risky should change as expertise increases. But, when workers experience improvisation as aversive, they are likely to use it only under duress — as a method of last resort. Thus, when studying improvisation as it currently exists in organizations, researchers are likely to be sampling behavior in unfavorable situations, when other approaches have already failed. If it were used in more favorable situations, improvisation might lead to very different outcomes and experiences from what we currently observe. Without both using improvisation in favorable situations and practicing improvisation regularly, it is difficult to imagine that people will find it pleasant or desirable. Researchers thus must go beyond single episodes of improvisation, asking: How do personal and situational factors interact over longer time horizons? Does improvisation 
become more enjoyable over time as people become more comfortable with it? Or, does it gradually burn out those who rely on it too heavily?

Second, as a creative process, the experience of improvising likely shapes the way in which it complements or replaces composition as a vehicle for generating creative outcomes. Rather than continue to search for a single process to describe creativity in organizations, we encourage scholars to conceptualize multiple creative processes-including both composition and improvisation - as a way to understand how and when these processes are undertaken. Because improvisation is means of creating that unites process and product - the thing and its making - it makes clear that creativity does not require divisions between them. Like Anderson and colleagues (2014), we are surprised that research emphasizes creations over creating; scholars have built typologies based on how novel or unique creations are (e.g., Madjar, Greenberg, \& Chen, 2011) or types of creative people (e.g., Elsbach \& Kramer, 2003), but seldom theorized differences in the processes by which they are created. Promising directions in theorizing creative processes emphasize changes in individuals' perspectives (Cronin \& Lowenstein, 2018), dialectics (Harvey, 2014; Tsoukas, 2009) and the socially constructed nature of creating (Sonenshein, 2016), but there is still more work to be done on this front. Research should explore how the experience of improvising shapes its relationship with composition, such as how people integrate improvisation into larger compositional processes or when unanticipated improvisations trigger composition.

\section{Methodological Considerations}

These questions are not easy ones to investigate empirically. The challenges of studying the experience of improvising are a special case of the studying any organizational process. 
Langley and colleagues' (2013) recommend that empirical research on processes in organizations should include data that is rich, varied, and longitudinal. We agree with this assessment and, below, articulate the specific challenges of collecting data on the experience of improvising, along with recommendations for overcoming them.

Identifying or creating improvisation. As mentioned above, improvisation may be avoided or hidden in many traditional, bureaucratic organizations. Thus, researchers need to identify situations in which it is likely to occur with sufficient regularity to study it. Prior research suggests that organizations that are seeking or encountering novelty are most likely to elicit improvisation. Organizations that are new (e.g., Baker \& Nelson, 2005; Hmielski \& Corbett, 2008) or changing rapidly (Brown \& Eisenhardt, 1997) are likely to improvise more frequently as a means of creating processes for new situations, making them promising settings for research on the experience of organizing. Further, organizations facing novel situations, such as industries that have recently experienced environmental shocks or that are entering new markets or lines of business are also more likely to improvise (e.g., Smets et al., 2012). Last, improvisation can be observed compositional processes, such as design firms that engage in brainstorming or rapid trial and error processes. Targeting these kinds of organizations will likely elicit a greater range of experiences of improvised action, allowing for more robust inquiry.

Other scholars have turned to eliciting improvisation in laboratory settings. Some psychologists have simply asked improvising artists to improvise in the laboratory, comparing improvised behavior (e.g., jazz solos, freestyle rap; improvised theater games) with nonimprovised behavior (e.g., playing a memorized piece, recreating prior improvisations) (Bengtsson et al., 2007; Limb \& Braun, 2008; Noy, Levit-Binun, \& Golland, 2015). It is easy to imagine similar approaches to studying organizational behaviors that are likely to involve 
improvisation, such as feedback-giving, negotiation, or creative teamwork. For instance, one might compare the experience of giving (or receiving) spontaneous feedback with prepared feedback. Alternatively, many tasks used for studying creativity, such as asking participants to make a radio advertisement (e.g., Gersick, 1989), could be adapted to allow minimal preparation and only "one take," so as to evoke improvisation. These approaches provide the benefit of nearly guaranteeing that improvisation occurs and making it more convenient to collect data on its experiences.

\section{Collect rich data that includes behaviors and experiences through multiple methods.}

To study the experience of improvising, one must both identify the behavior as improvisation and have data on its experience. However, both of these can be difficult. For good reasons, improvisation is often studied through post-hoc practitioner accounts - large-scale studies of improvisation often require retrospective reports because it is difficult to observe in real-time. However, like doctors who improvise in the ER (Batista et al., 2016), many practitioners may be hesitant to reveal the happenstance and spontaneous nature of improvisational creativity, especially when it clashes with established organizational norms and procedures. Further, people may engage in post-hoc sense-making, in which they develop narratives in which they infer that they must have intended to engage in a creative process after observing the results of their own actions. In highly regulated and routinized industries and professions, people may try to hide their improvisations, or forget episodes of improvisation quickly, making it difficult for researchers to access. In such circumstances, self-report methodologies, such as surveys and interviews, may fail to identify instances of improvisation.

Because improvisation is especially likely to be written out of people's accounts of their own behavior, researchers should triangulate between self-report and observational methods to 
robustly document the experience of improvising. In addition, because improvisation is a momentary behavior, the time lag between behavior and data collection should be minimized. For qualitative studies, which are most consonant with the pragmatic and non-dualistic theoretical lenses we advocate above, this means that interviews should take place as soon as possible after focal improvised events are observed. For experimental studies, this can mean both post-hoc reports on subjective experience, as well as real-time physiological data collection, such as fMRI (e.g., see Beatty, 2015 for a review of improvisation and fMRI), galvanic skin response, or blood pressure changes (see Akinola, 2010 for a review of using physiological measurements in organizational research). These methods also provide the opportunity to further assess the validity of survey measures of improvisation, which have seldom been used in combination with observed behavior. By using survey measures in combination with qualitative observation or experimental settings eliciting improvisation, scholars can also assess the potential effects of hiding or under-reporting improvisation that may currently exist in the literature.

Clarify levels of analysis. As a process, improvising presents two ambiguities about level of analysis. First is the question of how "collective" the analysis of improvisation should be: Is the unit of analysis a specific behavior, an individual, group, or organization (Hackman, 2003)? A key problem with integrating subjective experience into the study of improvisation in organizations is that scholars have examined improvisation at many different levels of analysis: some research focuses on individuals improvising, some on small groups improvising collectively, and others on whole organizations improvising. However, collectives like whole organizations do not have subjective experiences - the people who compose them do. For instance, is the experience of a firefighter trying to save his life (e.g., Weick, 1993) has the same experience as a member of an organization that has improvised entry to a new market (e.g., 
Bingham, 2009)? Indeed, how can the aspects of the experience of improvising detailed here inform organization-level improvisation?

Following Cunha and colleagues (2017), we agree that researchers need to be more specific about how improvisation crosses levels of analysis, including how collective improvisation affects the experiences of those involved, and how those experiences may or may not come to be shared. Improvisation, by its nature, occurs at the intersection of action and cognition; it encompasses how people think and feel in the situations they exist in and how the relate to one another in the moment. Such practices do not have inherent levels of analysis and, in fact, can be used by scholars to link them (e.g., Bourdieu, 1977; Emirbayer \& Johnson, 2008). Several studies have showed how improvisation can link the actions of individuals to the group (e.g., Bechky \& Okhuysen, 2011), organization (e.g., Miner et al., 2001), and field (e.g., Smets et al 2012). To create such specifications, scholars should explicate the links between individuals, groups, and organizations improvisational behaviors.

Further, ascribing improvisation to whole organizations, in which individuals may not be aware of each other's real-time actions, risks excessively anthropomorphizing organizations. It is difficult to conceptualize an organization feeling fear, exhilaration, or transcendence without discussing the experience of individual members. In our view, using the term "improvisation" in a way that does not involve the experience of improvising for the individuals involved dilutes the power of the concept. Although peoples' subjective experiences in organizations can be contagious and mutually influential (e.g., Barsade, 2002), theorizing organizations as single, monolithic actors can hide cross-level and inter-group interactions (Kahn et al., 2018). In specifying the location of experiences within an organization, scholars can articulate how experience influences other organizational processes and outcomes. Attending to the subjective 
experience of organizational members will help ground the concept of organizational improvisation in the phenomenology of those who practice it and keep it clearly differentiated from related organizational activities, such as exploration or innovation.

Level of analysis is also an issue with time scale. As with any process, one can progressively decompose activity into progressively smaller periods of time or aggregate them into larger ones. The experience of improvising, in particular, is meaningful only at relatively short time-scales - encompassing minutes, not days or weeks. We encourage scholars to take an episodic approach to understanding improvisation, but to view those episodes as occurring over these shorter time periods. The benefit of this approach is that it creates more instances of improvisation to study within a single research site, and allows researchers to examine how one episode of improvisation influences future actions, people, and situations.

\section{Limitations}

Our analysis of the experience of improvising in organization and recommendations for future research have several limitations. We argue that improvisation is under-used and hidden in organizations because it is experienced so negatively due to norms toward rationality and goaldirected action. We do not mean to imply, however, that improvisation is inherently good for all organizations or situations. More research is needed to specify when and for whom improvisation leads to desirable results. For instance, improvising may be extremely useful for nascent ventures with few established procedures and low costs of failure, or in rapidly changing environments. However, organizations in stable environments, many established procedures, with high failure costs may need to minimize improvisation. That said, there are many accounts of improvisation in settings with many established procedures that suddenly find themselves in 
new situations (Batista et al., 2016; Hutchins, 1991; Weick, 1993), such that the perception of an environment as stable is often fleeting or illusory. Until improvisation is tried and practiced in situations that are not dire, we, as researchers, it will be difficult to assess its true potential.

Second, empirical research on improvisation has relied heavily on interpretivist qualitative studies, which have been difficult to reconcile with positivistic quantitative studies. In particular, the literature on organizational creativity is largely grounded in social psychology, with positivist research traditions (Anderson et al., 2014). Integrating the literatures on improvisation and creativity may involve a clash of epistemology that cannot be solved with different questions and methods; adopting some of these theoretical lenses may lead to fractures in the literature, rather than reconciliation. Although this is a risk, we hope that scholars from both literatures will increasingly understand contributions from the other over time, building on rich, multi-method research (e.g., qualitative observation and survey validation) and clarity about levels of analysis.

Last, we did not account for what many scholars have called different forms of improvisation, usually defined according to the novelty of the response to differentiate between small variations and wholesale de novo creations (e.g., Weick, 1998). This is similar to some in creativity who research big and little "c" creativity, based on how novel the intended solutions are (e.g., Kaufman \& Beghetto, 2009). We avoid these distinctions because we believe the relationship between cognition and action — uniting design and execution — is what triggers the experience of improvising. In other words, it is the experience of novelty for the person that defines improvisation, rather than how novel the outside world judges something to be. However, it is possible that these forms of improvising constitute qualitatively different phenomenon, with both different outcomes and experiences and requiring separate theories and 
concepts. Even if this is the case, our recommendations for research should allow scholars to arrive at this conclusion more quickly.

\section{Implications for Practice}

Our analysis also has implications for practice. Managers should examine whether they are putting workers in situations requiring improvisation, yet acting in ways that make the experience more negative or minimize its chances of success. When asking employees to deal with new situations, leaders and managers need to take steps to dampen, rather than heighten, the perilous dimension of the experience of improvising so that members are willing and able to improvise when necessary. In such instances, embracing risk and letting go of the familiar can prevent the stress of the situation from overwhelming exhilaration inherent in improvising (Barrett, 2000). When organizations expect the unexpected, managers need to make sure that employees develop and understand minimal structures that scaffold their actions (Barrett, 1998; Brown \& Eisenhardt, 1997), and seek to develop a culture that celebrates experimentation (Lee, Edmondson, Thomke, \& Worline, 2004). These steps should allow managers to more accurately assess when improvising might be beneficial or harmful to organizational goals.

\section{Conclusion}

The experience of improvising is important for organizational scholars to attend to both because human experience is, on its own, an important outcome of organizational life, and because the "exhilarating and perilous" nature of improvisation shapes the conditions under which people seek out and avoid it. Because improvisation is an important source of creativity, scholars of creativity should further develop process theories that incorporate its experience. 
Because improvisation is also a creative process, we hope that scholars of improvisation will also draw more on insights from creativity research, bringing to bear the accounts of the experience and outcomes of improvising. In bringing together these two research literatures around the topic of the experience of the improvising, we will have a richer and phenomenologically grounded view of both improvisation and creativity in organizations.

The experience of ideating and enacting without the possibility of revision is central to understanding what improvisation is. That experience is both fearful and exhilarating, holding within it the both possibility of transcendence and failure. Focusing more on this process will tell us more about what role improvisation plays in organizational life. As Barrett (2012) argued: Jazz musicians seek to live lives of radical receptivity. Human beings are at their best when they do the same -- when they are open to the world, able to notice expansive horizons of possibility, fully engaged in skillful activity, and living in contexts that summon responses that lead to new discoveries.

The question is not necessarily whether improvising routinely makes you feel good; clearly, it often does not. Rather, the question is what happens when it is absent. Although humans may be able to live without improvising, minimizing the opportunity to do so in organizations or forcing people to hide it can reduce the opportunity to experience a central tension in life, one that provides the opportunity to learn, grow and create. We hope that future research will further represent such experiences as part of creative processes in organizations. 


\section{References}

Akinola, M. (2010). Measuring the pulse of an organization: Integrating physiological measures into the organizational scholar's toolbox. Research in Organizational Behavior, 30, 203223. doi: 10.1016/j.riob.2010.09.003

Amabile, T. M. (1996). Creativity in context. Boulder, CO: Westview Press.

Amabile, T. M., Barsade, S. G., Mueller, J. S., \& Staw, B. M. (2005). Affect and creativity at work. Administrative Science Quarterly, 50(3), 367-403.

Amabile, T. M., \& Kramer, S. J. (2011). The progress principle: Using small wins to ignite joy, engagement, and creativity at work. Cambridge, MA: Harvard Business School Press.

Amabile, T. M., \& Pratt, M. G. (2016). The dynamic componential model of creativity and innovation in organizations: Making progress, making meaning. Research in Organizational Behavior. doi: 10.1016/j.riob.2016.10.001

Anderson, N., Potočnik, K., \& Zhou, J. (2014). Innovation and creativity in organizations. Journal of Management, 40, 1297-1333. doi: 10.1177/0149206314527128

Baker, T., \& Nelson, R. E. (2005). Creating something from nothing: Resource construction through entrepreneurial bricolage. Administrative Science Quarterly, 50(3), 329-366.

Balachandra, L., Barrett, F., Bellman, H., Fisher, C., \& Susskind, L. (2005). Improvisation and mediation: Balancing acts. Negotiation Journal, 21(4), 425-434.

Barrett, F. J. (1998). Creativity and improvisation in jazz and organizations: Implications for organizational learning. Organization Science, 9(5), 605-622.

Barrett, F. J. (2000). Cultivating an aesthetic of unfolding: Jazz improvisation as a selforganizing system. In S. Linstead \& H. J. Hopf (Eds.), The aesthetics of organizations (pp. 228-245). London: Sage Press. 
Barrett, F. J. (2012). Yes to the mess: Surprising leadership lessons from jazz. Boston, MA:

Harvard Business Review Press.

Barsade, S. G. (2002). The ripple effect: Emotional contagion and its influence on group behavior. Administrative Science Quarterly, 47(4), 644-675.

Bastien, D. T., \& Hostager, T. J. (1988). Jazz as a process of organizational innovation, jazz as a process of organizational innovation. Communication Research, 15, 582-602. doi: $10.1177 / 009365088015005005$

Batista, M. da G., Clegg, S., Cunha, M. P., Giustiniano, L., \& Rego, A. (2016). Improvising prescription: Evidence from the emergency room. British Journal of Management, 27, 406425. doi: $10.1111 / 1467-8551.12143$

Beaty, R. E. (2015). The neuroscience of musical improvisation. Neuroscience \& Biobehavioral Reviews, 51, 108-117. doi: 10.1016/j.neubiorev.2015.01.004

Bechky, B. A., \& Okhuysen, G. A. (2011). Expecting the unexpected? How SWAT officers and film crews handle surprises. Academy of Management Journal, 54(2), 239-261.

Bengtsson, S. L., Csikszentmihalyi, M., Ullén, F., 2007. Cortical regions involved in the generation of musical structures during improvisation in pianists. Journal of Cognitive Neuroscience, 19(5), 830.

Berliner, P. (1994). Thinking in jazz: The infinite art of improvisation. Chicago: University of Chicago Press.

Bigley, G. A., \& Roberts, K. H. (2001). The incident command system: High-reliability organizing for complex and volatile task environments. Academy of Management Journal, 44, 1281-1299. doi: 10.2307/3069401 
Bingham, C. B. (2009). Oscillating improvisation: How entrepreneurial firms create success in foreign market entries over time. Strategic Entrepreneurship Journal, 3, 321-345. doi: $10.1002 / \mathrm{sej} .77$

Bourdieu, P. (1977). Outline of a theory of practice. (R. Nice, Trans). Cambridge, UK: Cambridge University Press.

Brown, S. L., \& Eisenhardt, K. M. (1997). The art of continuous change: Linking complexity theory and time-paced evolution in relentlessly shifting organizations. Administrative Science Quarterly, 42(1), 1-34.

Cronin, M. A., \& Loewenstein, J. (2018). The craft of creativity. Stanford, CA: Stanford University Press.

Crossan, M., Cunha, M. P., Vera, D., \& Cunha, O. (2005). Time and organizational improvisation. Academy of Management Review, 30(1), 129-145.

Crossan, M., \& Sorrenti, M. (1997). Making sense of improvisation. Advances in Strategic Management, 14(1), 155-180.

Csikszentmihalyi, M. (1990). Flow: The psychology of optimal experience. New York: Harper and Row.

Cunha, M. P., Cunha, J. V., \& Kamoche, K. (1999). Organizational improvisation: What, when, how and why. International Journal of Management Reviews, 1(3), 299.

Cunha, M. P., Miner, A. S., \& Antonacopoulou, E. (2017). Improvisation processes in organizations. In A. Langley \& H. Tsoukas (Eds.), SAGE Handbook of Process Organization Studies (pp. 559-573). London: Sage.

Dane, E., \& Pratt, M. G. (2007). Exploring intuition and its role in managerial decision making. Academy of Management Review, 32(1), 33-54. 
Davis, M., \& Troupe, Q. (1990). Miles Davis: The Autobiography. London: Picador Books.

Dörfler, V., \& Ackermann, F. (2012). Understanding intuition: The case for two forms of intuition. Management Learning, 43, 545-564. doi: 10.1177/1350507611434686

Drazin, R., Glynn, M. A., \& Kazanjian, R. K. (1999). Multilevel theorizing about creativity in organizations: A sensemaking perspective. Academy of Management Review, 24(2), 286307.

Eisenberg, E. M. (1990). Jamming: Transcendence through organizing. Communication Research, 17, 139-164. doi: 10.1177/009365090017002001

Eisenhardt, K. M., \& Sull, D. N. (2001). Strategy as simple rules. Harvard Business Review, 79(1), 106-116.

Eisenhardt, K., \& Tabrizi, B. N. (1995). Accelerating adaptive processes: Product innovation in the global computer industry. Administrative Science Quarterly, 40(1), 84-110.

Elsbach, K. D., \& Hargadon, A. B. (2006). Enhancing creativity through "mindless" work: A framework of workday design. Organization Science, 17(4), 470-483.

Elsbach, K. D., \& Kramer, R. M. (2003). Assessing creativity in Hollywood pitch meetings: evidence for a dual-process model of creativity judgments. Academy of Management Journal, 46, 283-301. doi: 10.2307/30040623

Emirbayer, M., \& Johnson, V. (2008). Bourdieu and organizational analysis. Theory and Society, 37(1), 1-44.

Fisher, C. M., \& Amabile, T. M. (2009). Creativity, improvisation and organizations. In T. Rickards, M. A. Runco, \& S. Moger (Eds.), The Routledge companion to creativity (pp. 1324). New York: Routledge. 
Fisher, C. M., Pillemer, J., \& Amabile, T. M. (2018). Deep help in complex project work:

Guiding and path-clearing across difficult terrain. Academy of Management Journal, 61, 1524-1553. doi: 10.5465/amj.2016.0207

Fong, C. T. (2006). The effects of emotional ambivalence on creativity. Academy of Management Journal, 49, 1016-1030. doi: 10.5465/amj.2006.22798182

George, J. M., \& Zhou, J. (2002). Understanding when bad moods foster creativity and good ones don't: The role of context and clarity of feelings. Journal of Applied Psychology, 87(4), $687-697$.

Gergen, K. J. (1985). The social constructionist movement in modern psychology. American Psychologist, 40(3), 266.

Gersick, C. J. G. (1989). Marking time: Predictable transitions in task groups. Academy of Management Journal, 32(2), 274-309.

Gilson, L. L., \& Litchfield, R. C. (2017). Idea collections: A link between creativity and innovation. Innovation, 19, 80-85. doi: 10.1080/14479338.2016.1270765

Good, D. J., Lyddy, C. J., Glomb, T. M., Bono, J. E., Brown, K. W., Duffy, M. K., ... Lazar, S. W. (2016). Contemplating mindfulness at work an integrative review. Journal of Management, 42(1), 114-142.

Gough, H. G. (1979). A creative personality scale for the Adjective Check List. Journal of Personality and Social Psychology, 37(8), 1398.

Hackman, J. R. (2003). Learning more by crossing levels: Evidence from airplanes, hospitals, and orchestras. Journal of Organizational Behavior, 24(8), 905-922. 
Hadida, A. L., Tarvainen, W., \& Rose, J. (2015). Organizational improvisation: A consolidating review and framework. International Journal of Management Reviews, 17, 437-459. doi: 10.1111/ijmr.12047

Hargadon, A. B., \& Bechky, B. A. (2006). When collections of creatives become creative collectives: a field study of problem solving at work. Organization Science, 17(4), 484-500.

Harvey, S. (2014). Creative synthesis: Exploring the process of extraordinary group creativity. Academy of Management Review, 39, 324-343. doi: 10.5465/amr.2012.0224

Harvey, S., \& Kou, C.-Y. (2013). Collective engagement in creative tasks: the role of evaluation in the creative process in groups. Administrative Science Quarterly, 58, 346-386. doi: $10.1177 / 0001839213498591$

Hatch, M. J. (1999). Exploring the empty spaces of organizing: how improvisational jazz helps redescribe organizational structure. Organization Studies, 20(1), 75-100.

Heidegger, M. (1962). Being and time. New York: Harper and Row.

Hélie, S., \& Sun, R. (2010). Incubation, insight, and creative problem solving: A unified theory and a connectionist model. Psychological Review, 117, 994-1024. doi: 10.1037/a0019532

Hmieleski, K. M., \& Corbett, A. C. (2008). The contrasting interaction effects of improvisational behavior with entrepreneurial self-efficacy on new venture performance and entrepreneur work satisfaction. Journal of Business Venturing, 23, 482-496. doi: 10.1016/j.jbusvent.2007.04.002

Hutchins, E. (1991). Organizing work by adaptation. Organization Science, 2(1), 14-39.

Joas, H. (1996). The creativity of action. Chicago: University of Chicago Press. 
Kahn, W., Barton, M., Fisher, C. M., Heaphy, E., Reid, E., \& Rouse, E. (2018). The geography of strain: Organizational resilience as a function of intergroup relations. Academy of Management Review, 43, 509-529. doi: 10.5465/amr.2016.0004

Kaufman, J. C., \& Beghetto, R. A. (2009). Beyond big and little: The four c model of creativity. Review of General Psychology, 13, 1-12. doi: 10.1037/a0013688

Langley, A. (1999). Strategies for theorizing from process data. Academy of Management Review, 24(4), 691-710.

Langley, A., Smallman, C., Tsoukas, H., \& Van de Ven, A. H. (2013). Process studies of change in organization and management: Unveiling temporality, activity, and flow. Academy of Management Journal, 56, 1-13. doi: 10.5465/amj.2013.4001

Lazendorfer, J. (2015, February) 15 facts about Dead Poets Society. Mentalfloss.com. Retrieved from: http://mentalfloss.com/article/59232/15-facts-about-dead-poets-society

Lee, F., Edmondson, A. C., Thomke, S., \& Worline, M. (2004). The mixed effects of inconsistency on experimentation in organizations. Organization Science, 15, 310-326. doi: 10.1287/orsc. 1040.0076

Leybourne, S., \& Sadler-Smith, E. (2006). The role of intuition and improvisation in project management. International Journal of Project Management, 24, 483-492. doi: 10.1016/j.ijproman.2006.03.007

Limb, C. L., Braun, A. R., 2008. Neural substrates of spontaneous musical performance: An fMRI study of jazz improvisation. PLOS ONE, 3, e1679.

Long Lingo, E., Fisher, C. M., \& McGinn, K. L. (2014). Negotiation processes as sources of (and solutions to) interorganizational conflict. In O. B. Ayoko, N. M. Ashkanasy, \& K. A. 
Jehn (Eds.), Handbook of Conflict Management Research (pp. 308-327). Cheltenham, UK: Edward Elgar Publishing Limited.

Lu, J. G., Akinola, M., \& Mason, M. F. (2017). "Switching on” creativity: Task switching can increase creativity by reducing cognitive fixation. Organizational Behavior and Human Decision Processes, 139, 63-75. doi: 10.1016/j.obhdp.2017.01.005

Madjar, N., Greenberg, E., \& Chen, Z. (2011). Factors for radical creativity, incremental creativity, and routine, noncreative performance. Journal of Applied Psychology, 96(4), 730.

Madjar, N., \& Shalley, C. E. (2008). Multiple tasks' and multiple goals' effect on creativity: Forced incubation or just a distraction? Journal of Management, 34, 786-805. doi: $10.1177 / 0149206308318611$

Mainemelis, C. (2001). When the muse takes it all: A model for the experience of timelessness in organizations. Academy of Management Review, 26, 548-565. doi: 10.2307/3560241

Mainemelis, C. (2002). Time and timelessness: Creativity in (and out of) the temporal dimension. Creativity Research Journal, 14, 227-238. doi: 10.1207/S15326934CRJ1402_9

Mainemelis, C. (2010). Stealing fire: Creative deviance in the evolution of new ideas. Academy of Management Review, 35(4), 558-578.

Mead, G. H. (1934). Mind, self and society. (C. W. Morris, Ed.) (Vol. 111). Chicago: Chicago University of Chicago Press.

Miner, A. S., Bassoff, P., \& Moorman, C. (2001). Organizational improvisation and learning: A field study. Administrative Science Quarterly, 46, 304. doi: 10.2307/2667089

Miron-Spektor, E., Gino, F., \& Argote, L. (2011). Paradoxical frames and creative sparks: Enhancing individual creativity through conflict and integration. Organizational Behavior and Human Decision Processes, 116, 229-240. doi: 10.1016/j.obhdp.2011.03.006 
Mueller, J. S., Melwani, S., \& Goncalo, J. A. (2012). The bias against creativity: Why people desire but reject creative ideas. Psychological Science, 23, 13-17. doi: $10.1177 / 0956797611421018$

Nachmanovitch, S. (1990). Free play: Improvisation in life and art. New York: Penguin Putnam.

Nonaka, I. (1994). A dynamic theory of organizational knowledge creation. Organization Science, 5(1), 14-37.

Noy, L., Levit-Binun, N., \& Golland, Y. (2015). Being in the zone: physiological markers of togetherness in joint improvisation. Frontiers in Human Neuroscience, 9, 1-14. doi: 10.3389/fnhum.2015.00187

Orlikowski, W. J. (1996). Improvising organizational transformation over time: A situated change perspective. Information Systems Research, 7(1), 63-92.

Peplowski, K. (1998). The process of improvisation. Organization Science, 9(5), 560-561.

Perry-Smith, J. E., \& Mannucci, P. V. (2017). From creativity to innovation: The social network drivers of the four phases of the idea journey. Academy of Management Review, 42, 53-79. doi: 10.5465/amr.2014.0462

Rescher, N. (1996). Process metaphysics: An introduction to process philosophy. Albany, NY: State University of New York Press.

Sawyer, R. K. (2000). Improvisation and the creative process: Dewey, Collingwood, and the aesthetics of spontaneity. The Journal of Aesthetics and Art Criticism, 58(2), 149-161.

Smets, M., Morris, T., \& Greenwood, R. (2012). From practice to field: A multilevel model of practice-driven institutional change. Academy of Management Journal, 55, 877-904. doi: 10.5465/amj.2010.0013 
Sonenshein, S. (2016). Routines and creativity: From dualism to duality. Organization Science, 27, 739-758. doi: 10.1287/orsc.2016.1044

Spolin, V. (1983). Improvisation for the theater: A handbook of teaching and directing techniques. Evanston, IL: Northwestern University Press.

Sutton, R. I., \& Hargadon, A. (1996). Brainstorming groups in context: Effectiveness in a product design firm. Administrative Science Quarterly, 41(4), 685-718.

Stierand, M., Dörfler, V., \& MacBryde, J. (2014). Creativity and innovation in haute cuisine: Towards a systemic model. Creativity \& Innovation Management, 23, 15-28. doi: 10.1111/caim.12050

Tsoukas, H. (2009). A dialogical approach to the creation of new knowledge in organizations. Organization Science, 20(6), 941-957.

Tsoukas, H., \& Chia, R. (2002). On organizational becoming: Rethinking organizational change. Organization Science, 13(5), 567-582.

Vera, D., \& Crossan, M. (2004). Theatrical improvisation: lessons for organizations. Organization Studies, 25, 727-749. doi: 10.1177/0170840604042412

Vera, D., \& Crossan, M. (2005). Improvisation and innovative performance in teams. Organization Science, 16, 203-224. doi: 10.1287/orsc.1050.0126

Vera, D., Nemanich, L., Vélez-Castrillón, S., \& Werner, S. (2016). Knowledge-based and contextual factors associated with R\&D teams' improvisation capability. Journal of Management, 42, 1874-1903. doi: 10.1177/0149206314530168

Wallas, G. (1926). The art of thought. New York: Harcourt, Brace and Company. Weick, K. E. (1993). The collapse of sensemaking in organizations: The Mann Gulch disaster. Administrative Science Quarterly, 38(4), 628-652. 
Weick, K. E. (1998). Introductory essay: Improvisation as a mindset for organizational analysis. Organization Science, 9(5), 543-555.

Yanow, D., \& Tsoukas, H. (2009). What is reflection-in-action? A phenomenological account. Journal of Management Studies, 46, 1339-1364. doi: 10.1111/j.1467-6486.2009.00859.x

Zhou, J. (2003). When the presence of creative coworkers is related to creativity: role of supervisor close monitoring, developmental feedback, and creative personality. Journal of Applied Psychology, 88, 413-422. doi: 10.1037/0021-9010.88.3.413 
Colin M. Fisher (colin.fisher@ucl.ac.uk) is an assistant professor of Organisations and Innovation at UCL School of Management. He studies the temporal dynamics of team leadership, helping, creativity and improvisation. Colin received his Ph.D. in organizational behavior from Harvard University while moonlighting as a jazz trumpet player, most notably with Either/Orchestra.

Frank J. Barrett (fbarrett@nps.edu) is Professor of Management and Global Public Policy at the Naval Postgraduate School. He has written and lectured widely on social constructionism, appreciative inquiry, organizational change, jazz improvisation and organizational learning. $\mathrm{He}$ is also an active jazz pianist, notably with the Tommy Dorsey Orchestra. 